\section{Control acelerado de la rubéola y prevención del síndrome de rubéola congénita en las Américas}

\author{
Carlos Castillo-Solórzano ${ }^{1}$ \\ y Ciro A. de Quadros ${ }^{1}$
}

Con la adopción en 1994 de la iniciativa para erradicar el sarampión del continente americano, se pusieron en marcha estrategias de vacunación encaminadas a reducir rápidamente el número de casos nuevos y a interrumpir la transmisión autóctona. Además, se instituyó, mejoró y fortaleció la vigilancia epidemiológica del sarampión, de la cual se derivaron datos que permitieron conocer la circulación del virus de la rubéola en diferentes países de la Región. En aproximadamente 25\% de los casos de sarampión que son notificados, el diagnóstico de laboratorio confirma que se trata de rubéola. Una cuidadosa revisión de los datos sobre la rubéola y el síndrome de rubéola congénita (SRC) reveló que cada año nacen más de 20000 niños con SRC en las Américas (1), aunque no haya grandes epidemias. En los brotes que se produjeron en los años noventa en Estados Unidos de América, la incidencia en personas hispanas se incrementó de 0,06 a 0,97 por 100000 habitantes en 1998. Arkansas notificó un brote en 1999 en el cual 83\% de los casos ocurrieron en inmigrantes de origen hispano, y entre 1997 y 1999 83\% de los 24 niños que nacieron con SRC fueron hijos de madres hispanas (2).

La rubéola se consideraba una enfermedad viral inocua hasta que se reconoció su teratogenia. Cuando la mujer embarazada se expone a la enfermedad, hay un riesgo de que el producto de su embarazo contraiga el SRC, cuyas consecuencias pueden ser el aborto espontáneo o terapéutico, el bajo peso al nacer o algunos defectos congénitos como la sordera, la ceguera, las anomalías cardiovasculares $\mathrm{y}$, en ocasiones, la muerte prematura.

El SRC se asocia con una gran morbilidad y mortalidad y con costos elevados. Los costos directos corresponden a la atención médica y a los servicios hospitalarios necesarios en la etapa aguda, a la atención de largo plazo y a la asistencia institucional y educación especial. La atención que requiere durante toda la vida un caso de SRC cuesta entre US\$ 50000 en Barbados y US\$ 63990 en Guyana, por poner un ejemplo. En países del Caribe de habla inglesa, los costos de tratar y rehabilitar a los 1500 casos de SRC que se estima podrían ocurrir en los próximos 15 años si no se aplica la vacuna ascenderían a US\$ 60 millones, mientras que la estrategia de eliminación costaría menos de US\$ 5 millones. En otras palabra, los costos del programa de eliminación se estiman en $7 \%$ del costo total de la atención y rehabilitación de los casos

División de Vacunas e Inmunización, Organización Panamerican de la Salud, Washington, D.C., Estados Unidos de América. 
de SRC, y la razón de los beneficios al costo de la estrategia para interrumpir la transmisión de la rubéola y prevenir el SRC es de 13,3:1 (3). En Estados Unidos esta razón, en el caso de la vacuna contra el sarampión, la rubéola y la parotiditis (SRP) es de 21,3:1, y en el de solo el componente antirrubéola, de $11,1: 1$.

A partir de esta importante información, se ha demostrado claramente que la rubéola y el SRC constituyen grandes problemas de salud pública cuyo impacto económico en los presupuestos gubernamentales justifica tomar medidas de control y prevención. Ante la disponibilidad de varias vacunas seguras, eficaces y baratas - de tipo monovalente o combinado-, en abril de 1998 el Consejo de Desarrollo Humano y Social de la Comunidad del Caribe (CARICOM) aprobó una resolución afirmando que se harían todos lo esfuerzos posibles por eliminar la rubéola y prevenir el SRC en la subregión caribeña. Asimismo, el Consejo instó a la Organización Panamericana de la Salud (OPS) a coordinar la movilización de recursos y a dar apoyo técnico para esta iniciativa (3). Seguidamente, el Grupo Técnico Asesor (GAT) en materia de enfermedades prevenibles por vacunas de la OPS recomendó poner en práctica una iniciativa regional orientada a prevenir la rubéola y el SRC.

La iniciativa se centra en dos áreas: la adopción de estrategias adecuadas de vacunación y la vigilancia epidemiológica. La primera está orientada a introducir la vacuna contra la rubéola en los esquemas nacionales de vacunación y a facilitar el control y la prevención de esta enfermedad y del SRC. La segunda se encamina a establecer un sistema de vigilancia epidemiológica sensible, sencillo y eficaz para el sarampión, la rubéola y el SRC, en el cual se usen técnicas adecuadas para hacer el diagnóstico por laboratorio y aislar el virus causal $(4,5)$.

A la fecha, 37 países y territorios de la Región han introducido la vacuna con un componente antirrubéola, que se ha de administrar a más de $90 \%$ de los niños de un año, en los programas de vacunación infantil; los cuatro países que aún no la han incorporado se proponen hacerlo durante este año y el próximo. De igual manera, la mayoría de los países están usando la vacuna combinada contra sarampión y la rubéola como parte de las campañas de seguimiento contra el sarampión que se dirige cada 4 años a niños de 1 a 4 años de edad.

En los últimos años, el Caribe de habla inglesa (1998-2001) y Costa Rica (2001) han llevando a cabo campañas de vacunación masiva, destinadas a hombres y mujeres, con objeto de prevenir y controlar rápidamente tanto la rubéola como el SRC. En cambio, Chile (1999) y Brasil (2001-2002) han dirigido campañas de vacunación masiva contra la rubéola a las mujeres solamente, a fin de prevenir y controlar de inmediato el SRC. Las edades diana se seleccionaron teniendo en cuenta el impacto de la vacuna en la epidemiología de la rubéola y del SRC, y el efecto de las campañas de vacunación realizadas anteriormente. Los resultados alcanzados han sido buenos, habiéndose logrado coberturas superiores a 95\% en algunos países. Los países del Caribe que no han alcanzado coberturas superiores a esta cifra continúan haciendo esfuerzos por llegar a la meta. El uso de la vacuna combinada contra el sarampión y la rubéola permite, además, consolidar la erradicación del sarampión (6).

Las experiencias y lecciones aprendidas en estas campañas en lo referente a las dificultades de vacunar en masa a la población adulta están aportando conocimientos que servirán de base para hacer modificaciones necesarias, reducir las disparidades, adquirir bases sólidas y fomentar la capacidad para promover y poner en práctica en un futuro iniciativas de este tipo en otros países de la Región. Para que las campañas surtan buenos resultados es crucial contar con 1) el compromiso, la motivación y el apoyo político, 2) la información epidemiológica y el análisis de costo-efectividad que respalda la decisión y el compromiso, 3) la participación decidida de las sociedades médicas y científicas, 4) una campaña cuya organización esté claramente definida, 5) la implementación de estrategias adecuadas de movilización social y 6) una campaña que se lleve a cabo en un período corto. Asimismo, tener en cuenta ciertos aspectos técnicos -identificar a la población que se ha de vacunar, programar suficientes materiales biológicos e insumos, idear distintas estrategias para captar a la población diana, elaborar instrumentos de registro, monitoreo y evaluación sencillos, etc., es esencial, particularmente para que sea más eficiente la vacunación de los adultos. De igual manera, se deberá prestar atención a detalles prácticos importantes, lo cual implica elaborar un plan para garantizar la inocuidad de las inyecciones y la disposición final de las jeringas y coordinar las actividades con los bancos de sangre (7). En resumen, la inmunización representa un inmenso logro de la ciencia y un enorme ejemplo de organización social en beneficio del ser humano.

Es fundamental tener un sistema de vigilancia epidemiológica eficaz que pueda detectar la circulación del virus de la rubéola, y con esa finalidad OPS formó en 1998 un grupo de trabajo especial. El grupo concluyó que era preferible ampliar e integrar los esfuerzos hechos hasta el momento para erradicar el sarampión y mejorar la vigilancia de las enfermedades febriles y exantemáticas como fuentes de información sobre la rubéola. Las mejoras en todos los países de la capacidad para diagnosticar el sarampión mediante pruebas de 
laboratorio también han redundado en una mejor capacidad técnica nacional para diagnosticar la rubéola, y esta integración ha incrementado, a su vez, la sensibilidad de la vigilancia del sarampión: casos que parecían ser de rubéola han resultado ser de sarampión y viceversa, una vez aplicadas las pruebas de laboratorio (6). Según el análisis de sensibilidad y especificidad del sistema de vigilancia integrado en el año 2000, de todos los casos de rubéola confirmados por laboratorio, $57 \%$ fueron notificados como rubéola, y de los casos en los cuales el diagnóstico de rubéola se descartó, $64 \%$ no habían sido notificados como de rubéola.

El sistema regional para la vigilancia está documentando una mayor detección de casos de SRC e infección fetal. El diagnóstico de SRC puede ser sencillo si se dispone de una muestra de sangre del menor de un año, a cuyos resultados debe sumarse el criterio clínico. Dado que el SRC es poco frecuente, especialmente en periodos no epidémicos, y en vista de su importancia y de la limitada disponibilidad de datos, ahora se cuenta con una fuente de información adicional, la del Sistema de Información Perinatal (SIP 2002) del Centro Latinoamericano de Perinatología y Desarrollo Humano (CLAP) y el del Estudio Colaborativo Latinoamericano de Malformaciones Congénitas (ECLAMC), que se considera un buen instrumento para la detección y notificación de casos de SRC (7).

Las nuevas y mejores técnicas de vigilancia de laboratorio nos van a permitir conocer mejor los virus de la rubéola que circulan en la Región. En los últimos años se ha podido utilizar, en el caso de la rubéola, la determinación molecular del genotipo de las cepas, técnica epidemiológica de laboratorio que se usa para identificar los virus de la poliomielitis y el sarampión. Esta técnica nos permitirá comprender la fuente y la propagación de los brotes de rubéola y casos de SRC y la distribución de las distintas cepas víricas causales. Los pocos resultados obtenidos hasta ahora con muestras clínicas revelan que han circulado tres genotipos diferentes. Es indudable que en los países de la Región se impone la necesidad de tomar medidas para aislar el virus.

Se reconoce hoy en día la importancia de implementar estas estrategias para lograr el rápido control de la rubéola y la prevención del SRC, así como la necesidad de garantizar a la población, en particular a la más pobre, el acceso a los servicios de salud esenciales, como la inmunización. En este sentido ha sido crucial la participación de los socios de la OPS, tales como la Fundación March of Dimes, los Centros para el Control y la Prevención de Enfermedades (CDC) y la Agencia de los Estados Unidos para el Desarrollo Internacional, y del sector privado, representado por la Federación Latinoamericana de Obstetricia y Ginecología (FLASOG), que sostuvo reuniones para discutir la participación de las sociedades de obstetricia y ginecología de todos los países en la puesta en marcha de estas estrategias. La FLASOG acordó recomendar que cada una de estas sociedades buscara en su país el compromiso político y los recursos de cada gobierno, y que sus miembros participaran activamente en el control acelerado de la rubéola y en la prevención del SRC. Reiteró las recomendaciones del GTA, resaltando que las pruebas científicas confirman que la vacuna contra la rubéola es inocua durante el embarazo, aunque no se suele vacunar a una mujer embarazada para evitar el riesgo de que se implique a la vacuna si se llegaran a producir eventos adversos no relacionados con ella en el producto del embarazo. No se recomienda el aborto en mujeres que fueron vacunadas sin saber que estaban embarazadas. Finalmente, no es necesario aconsejar a las mujeres que eviten el embarazo después de la vacunación contra la rubéola.

La vigilancia nos demuestra que es posible lograr el control acelerado de la rubéola y la prevención del SRC mediante las estrategias implementadas en el Caribe de habla inglesa y los países de América Latina. También pone de manifiesto los logros alcanzados en la prevención de la enfermedad por países como Canadá, Cuba, Estados Unidos, Panamá y Uruguay donde se ha venido usando la vacuna contra la rubéola por varios años y donde grandes cohortes de mujeres en edad fértil están protegidas. Estos datos nos ratifican una vez más que la inmunización es una intervención de salud pública con muy altas razones de costo a beneficio y de costo a efectividad. El alto costo y el inmensurable sufrimiento humano ocasionado por el SRC se pueden prevenir.

El control acelerado de la rubéola y el SRC cuenta con la voluntad política, tiene viabilidad financiera, es racional desde un punto de vista técnico y es aceptable y factible en un sentido social. En la 43. ${ }^{a}$ Reunión del Consejo Directivo de la OPS, los Estados Miembros aprobaron la resolución CD43.R1 (2001) que resuelve, entre otros puntos, "Fortalecer los esfuerzos para reducir el número de mujeres en edad fértil susceptibles a la rubéola y prevenir los casos de SRC mediante la implementación de estrategias de vacunación acelerada contra la rubéola y acrecentar la vigilancia de la rubéola y SRC". Los Cuerpos Directivos también dieron a la OPS el mandato de participar activamente en esta iniciativa, que se ha convertido en una de las prioridades de la Organización.

Se ha examinado todo lo que se debe hacer para llevar adelante esta iniciativa; las estrategias y el conocimiento de todo lo que representa están dados, y el camino está señalado. Los retos para el futuro próximo son apoyar y fomentar la im- 
plementación de estrategias apropiadas de vacunación contra la rubéola en todos los países y mantener una cobertura mínima de vacunación superior al 95\% en cada cohorte de niños de un año. De igual manera, es preciso reforzar las actividades para integrar la vigilancia de la rubéola y el sarampión; seguir investigando los brotes de estas enfermedades y vigilando a todas las mujeres embarazadas que han contraído la rubéola; mejorar la vigilancia del SRC y la recolección de muestras para aislar el virus causal de cada brote, y crear la capacidad técnica para aislar el virus en los países.

Tal como ocurre con el programa de erradicación del sarampión, la importación de casos seguirá constituyendo la principal amenaza. Aun cuando se hagan esfuerzos extraordinarios para reducir los casos de rubéola y SRC en las Américas, la importación del virus puede continuar y solo se detendrá cuando los países de otras regiones del mundo realicen esfuerzos similares.

Estas estrategias aportan grandes beneficios en función de su costo y orientan a los gobiernos a la hora de decidir dónde invertir sus limitados recursos. Sin embargo, esta iniciativa encaminada a controlar aceleradamente la rubéola y a prevenir el
SRC requiere de recursos adicionales y puede ser financiada con la ayuda internacional, para lo cual la OPS está desempeñando una función catalítica en la formación de asociaciones y la consecución de aportes para fomentar la salud de la población del continente americano.

\section{SYNOPSIS}

\section{Accelerated rubella control and the prevention of congenital rubella syndrome}

Congenital rubella syndrome (CRS) is associated with substantial morbidity and mortality and with high costs. Today, as a result of improved vaccination and epidemiological surveillance efforts directed at eradicating measles from the Western Hemisphere, there has been a notable increase in the ability to detect, prevent, and control rubella and CRS. The importance of these measures is undeniable, and this piece examines the components that are essential in moving ahead to reduce these major public health problems in Latin America and the Caribbean. One step in that direction would be to integrate the surveillance of measles with that of rubella and CRS.

\section{REFERENCIAS}

1. Pan American Health Organization. Public Health Burden of Rubella and CRS. EPI Newsletter 1998;20(4):2-3.

2. Reef SE, Frey TK, Abernathy E, Burnett $\mathrm{CL}$, Icenogle J, McCauley MM, et al. The changing epidemiology of rubella in the 1990s: on the verge of elimination and new challenges for control and prevention. JAMA 2002;Jan 23-30;287(4):464-472.

3. Irons B, Lewis MJ, Dahl-Regis M, Castillo-Solórzano C, Carrasco PA, de Quadros CA. Strategies to eradicate rubella in the English-speaking Caribbean. Am J Public Health 2000;90(10):1545-1549.

4. Pan American Health Organization, Division of Vaccines and Immunization. Final report: conclusions and recommendations. 13th Meeting of the Technical Advisory Group on Vaccine Preventable Diseases, Canada, 1999.

5. Pan American Health Organization. Division of Vaccines and Immunization. Final report: conclusions and recommendations. 14th Meeting of the Technical
Advisory Group on Vaccine Preventable Diseases, Brazil, 2001.

6. Castillo-Solórzano C, Carrasco P, Tambini G, Ref. S, Brana M, de Quadros CA. New horizons in the control of rubella and prevention of congenital rubella Syndrome in the Americas. J Infect Dis. (En preparación).

7. Pan American Health Organization. Field Guide for the Accelerated Control of Rubella and Prevention of CRS. Washington, D.C.: PAHO; 2002. (Documento técnico, en preparación). 